\title{
Comparative Evaluation of Three Mixed Dentition Analyses and Formulation of Regression Equations for North Indian Population: A Cross-sectional Study
}

\author{
Suruchi Juneja ${ }^{1}$, Neeraj Mahajan² ${ }^{2}$ Harsimrit Kaur ${ }^{3}$, Kanika Gupta Verma ${ }^{1}$, Manish Sukhija ${ }^{4}$, Eenal Bhambri ${ }^{5}$
}

Background: The present study was undertaken to evaluate the accuracy of methods proposed by Tanaka and Johnston, Moyers, and Bernabé and Flores-Mir to forecast the mesiodistal dimensions of permanent canine and premolars in a North Indian population.

Methods: $\quad$ Mesiodistal tooth dimensions were measured from study models representing 68 male and 68 female subjects (aged 12-16 years) of North Indian descent. The mesiodistal dimensions of the teeth were measured using a digital Vernier caliper (providing measurements to $0.01 \mathrm{~mm}$ accuracy). The measurements of canine and premolars were summed up and compared with those derived from Tanaka and Johnston equations, Moyers probability tables $\left(75^{\text {th }}\right.$ percentile), and Bernabé and Flores-Mir equations.

Results: All the three methods exhibited overestimation of actual sum of permanent canine and premolars in both the arches and genders in this population. Because of the discrepancy observed, new regression analyses in the form of $\mathrm{Y}=\mathrm{A}+\mathrm{B}(\mathrm{X})$ were formulated similar to those proposed by Tanaka and Johnston originally, but separately for males and females. In males, the correlation coefficient between the sum of mesiodistal widths of mandibular incisors and the sum of widths of canine and premolars was 0.637 and 0.685 for maxilla and mandible, respectively. This value was 0.55 for maxilla and 0.64 for mandible in females.

\section{At a Glance Commentary}

Scientific background of the subject

Precise estimation of the mesiodistal dimensions of unerupted permanent canine and premolars is the key to diagnosis and management of space related dilemmas encountered in mixed dentition stage. Anthropological data reveals ethnic variations in the tooth sizes among various populations. There exists a need to evaluate the accuracy and modify the commonly employed methods for prediction of size of unerupted permanent canine and premolars.

\section{What this study adds to the field}

An overestimation of sizes of unerupted permanent canine and premolars was observed by Moyer's, Tanaka Johnston and Bernabe and Flores Mir methods in North Indian population. The regression equations were hence derived specifically for this population in an attempt to improve prediction accuracy.

Conclusion: All the methods evaluated in the study were found to be inaccurate and they overestimate the mesiodistal widths of permanent canine and premolars in North Indian population. Revised linear regression equations were derived using the data obtained from this population.

(Biomed J 2015;38:450-455)

\section{Key words: mesiodistal dimension, mixed dentition analysis, regression equations}

$\mathrm{M}$ ixed dentition analysis, used to estimate the size of unerupted permanent teeth, is high on the list of diagnostic priorities during developing occlusion. It is an important criterion in determining whether the treatment plan is going to involve serial extraction, guidance of eruption, space maintenance, space regaining, or just periodic

From the ${ }^{1}$ Department of Pedodontics and Preventive Dentistry, Surendera Dental College and Research Institute, Sri Ganganagar, Rajasthan, India; ${ }^{2}$ Department of Pedodontics and Preventive Dentistry, Guru Nanak Dev Dental College and Research Institute, Sunam, Punjab, India; ${ }^{3}$ Department of Pedodontics and Preventive Dentistry, Laxmi Bai Institute of Dental Sciences and Hospital, Patiala, Punjab, India; ${ }^{4}$ Department of Periodontology and Implantology, Surendera Dental College and Research Institute, Sri Ganganagar, Rajasthan, India; ${ }^{5}$ Department of Orthodontics and Dentofacial Orthopedics, Surendera Dental College and Research Institute, Sri Ganganagar, Rajasthan, India

Received: Aug. 14, 2014; Accepted: Jun. 17, 2015

Correspondence to: Dr. Suruchi Juneja, Department of Pedodontics and Preventive Dentistry, Surendera Dental College and Research Institute, Sri Ganganagar, Rajasthan, India. Power House Rd., Sri Ganganagar, Rajasthan - 335 001, India. Tel: 91-9829365880; E-mail: drsuruchijuneja@gmail.com

DOI: $10.4103 / 2319-4170.161333$ 
observation of the patient. ${ }^{[1]}$ Numerous methods of predicting the mesiodistal widths of unerupted canines and premolars have been reported. These methods use three distinct ways to achieve the purpose. The first employs direct measurements of the teeth from radiographs with or without the use of prediction formula. ${ }^{[2-4]}$ The second method utilizes prediction tables based on measurements of other erupted permanent teeth. ${ }^{[5-8]}$ The third method involves a combination of previous two methods, i.e. the use of prediction tables in association with measurements of erupted and unerupted teeth ${ }^{[4,9-11]}$ However, radiographic methods are not usually carried out because they are time consuming and the correlation coefficients between the real sizes of "reference teeth" and the "real values" of predicted teeth are not high enough to ensure a good prediction. ${ }^{[12]}$

Tanaka and Johnston and Moyers methods are based on the existence of a significant linear association between the sum of mesiodistal tooth widths of the lower permanent incisors and the sum of lower or upper permanent canines and premolars. Moyers devised a table giving the predicted mesiodistal widths of permanent canines and premolars on the basis of mandibular incisor widths, which has achieved widespread clinical acceptance. ${ }^{[6]}$ Tanaka and Johnston developed equations in an attempt to simplify mixed dentition space analysis. These were developed for North American Caucasian children and it is reasonable to question their use in other populations..$^{[7]}$

It is also noteworthy that Moyers has provided two sets of data tables, one for sexes combined, which does not correlate with the sexes separated data. Tanaka and Johnston method also provides data without considering sexual dimorphism. ${ }^{[7]}$ It is questionable to apply these methods which are based on pooled male and female data. Moreover, there is some evidence of secular trends of changing dimensions of the teeth, which may require progressive modifications of mixed dentition space analysis for different populations. ${ }^{[13]}$ Bernabé and Flores-Mir proposed the combination of mesiodistal dimensions of permanent upper and lower central incisors and upper first molars to be the best predictor for estimation of mesiodistal dimensions of unerupted teeth in Peruvian population. ${ }^{[14]}$

Since the relationship between tooth size and ethnic background cannot be denied, there exists a need to modify the mixed dentition analyses to various ethnic groups. There is a paucity of data regarding comparison of the sum of mesiodistal dimensions of permanent mandibular incisors and the sum of mandibular central incisors, maxillary central incisors, and first molars in prediction of mesiodistal widths of unerupted canine and premolars in North Indian population.

This study aimed to investigate the applicability of methods developed by Moyers, Tanaka and Johnston, and Bernabé and Flores-Mir for prediction of widths of unerupted caninessand premolars in North Indian population.

\section{METHODS}

The sample consisted of 136 study casts, both maxillary and mandibular, of subjects of North Indian lineage in the age group 12-16 years. The sample was selected from among patients attending Department of Pedodontics and Preventive Dentistry during the period from December 2013 to March 2014.

The selection criteria used were as follows:

- The subjects had North Indian ancestors from at least one previous generation

- All the permanent teeth to be measured, i.e., maxillary central incisors, mandibular incisors, maxillary first molars, and maxillary and mandibular canines and premolars, should be present and fully erupted

- The subjects should have no history of previous orthodontic treatment

- Intact dentition should be present with no evidence of proximal caries, restorations, fractures, or tooth wear that would alter the mesiodistal dimensions of teeth

- No obvious anomalies regarding number, form, size, or structure should be present.

The study was approved by the institutional ethical committee (No. SDCRI/IEC/2013/010, dated 14/12/13). Informed consent was taken from all the study subjects. Impressions for all the subjects were made in alginate impression material (Plastalgin; Septodont, Saint-Maur, France) and were poured using dental stone (Kaldent, dental stone type III; Kalabhai Ltd, Mumbai, India) without delay to prevent dimensional changes.

The mesiodistal dimensions of teeth were measured using a digital Vernier gauge providing measurements to $0.01 \mathrm{~mm}$ accuracy. The mesiodistal width of tooth was obtained by measuring the greatest distance between the contact points on proximal surfaces. The measurements were recorded by holding the caliper parallel to the occlusal surface and perpendicular to the long axis of the tooth. ${ }^{[3]}$ To gain easier access to interdental spaces, the measuring tips of the digital caliper were narrowed. To diminish ocular fatigue, not more than six sets of casts were measured per day.

Mandibular permanent central and lateral incisors, maxillary permanent central incisors and first molars, and maxillary and mandibular permanent canines and premolars were the teeth measured. All the measurements were made by the same investigator. Values obtained for the right and left posterior segments were averaged, so that there was one value for the maxillary canine and premolars and one value for the mandibular canine and premolars. To test the reliability of the measurements, 10 study models were randomly selected and were measured three times at an interval of 1 week. Pearson correlation statistical analysis was done and intra-examiner bias was found to be insignificant [Table 1]. 
Table 1: Statistical analysis showing intra-examiner reliability

\begin{tabular}{|c|c|c|c|c|c|c|c|c|c|}
\hline \multicolumn{5}{|c|}{ Maxilla } & \multicolumn{5}{|c|}{ Mandible } \\
\hline Tooth no. & $\begin{array}{l}\text { Mean } \\
\text { (in } \mathrm{mm} \text { ) }\end{array}$ & $\begin{array}{c}\mathrm{SD} \\
\text { (in } \mathrm{mm} \text { ) }\end{array}$ & $\begin{array}{l}\text { Pearson correlation } \\
\text { coefficient }(r)\end{array}$ & $\begin{array}{l}\text { Significance } \\
(p)\end{array}$ & Tooth no. & $\begin{array}{l}\text { Mean } \\
\text { (in mm) }\end{array}$ & $\begin{array}{c}\mathrm{SD} \\
\text { (in } \mathrm{mm} \text { ) }\end{array}$ & $\begin{array}{l}\text { Pearson correlation } \\
\text { coefficient }(r)\end{array}$ & $\begin{array}{l}\text { Significance } \\
\qquad(p)\end{array}$ \\
\hline 16 & 9.49 & 0.04 & 1 & - & 36 & 10.70 & 0.04 & 1 & - \\
\hline 15 & 5.90 & 0.04 & 0.93 & $0.246^{\dagger}$ & 35 & 6.53 & 0.06 & 0.19 & $0.879^{\dagger}$ \\
\hline 14 & 6.72 & 0.06 & 0.54 & $0.636^{\dagger}$ & 34 & 6.92 & 0.02 & 0.92 & $0.260^{\dagger}$ \\
\hline 13 & 7.04 & 0.10 & 0.00 & $0.998^{\dagger}$ & 33 & 7.05 & 0.02 & 0.80 & $0.407^{\dagger}$ \\
\hline 12 & 6.56 & 0.02 & 0.81 & $0.396^{\dagger}$ & 32 & 5.57 & 0.05 & 1.00 & $<0.001^{*}$ \\
\hline 11 & 8.09 & 0.03 & 0.79 & $0.425^{\dagger}$ & 31 & 4.97 & 0.03 & 0.50 & $0.667^{\dagger}$ \\
\hline 21 & 8.02 & 0.01 & 0.14 & $0.909^{\dagger}$ & 41 & 4.94 & 0.10 & 0.62 & $0.573^{\dagger}$ \\
\hline 22 & 6.75 & 0.07 & 0.21 & $0.861^{\dagger}$ & 42 & 5.70 & 0.03 & 0.50 & $0.667^{\dagger}$ \\
\hline 23 & 7.12 & 0.06 & 0.38 & $0.754^{\dagger}$ & 43 & 7.02 & 0.03 & 0.50 & $0.667^{\dagger}$ \\
\hline 24 & 6.84 & 0.05 & 0.15 & $0.902^{\dagger}$ & 44 & 6.60 & 0.07 & 0.56 & $0.619^{\dagger}$ \\
\hline 25 & 5.86 & 0.06 & 0.73 & $0.477^{\dagger}$ & 45 & 6.57 & 0.09 & 0.60 & $0.593^{\dagger}$ \\
\hline 26 & 9.31 & 0.09 & 0.43 & $0.717^{\dagger}$ & 46 & 10.50 & 0.02 & 0.92 & $0.260^{\dagger}$ \\
\hline
\end{tabular}

Abbreviations: SD: Standard deviation; ${ }^{*}$ : Highly significant; ${ }^{\dagger}$ : Insignificant

\section{Three prediction methods used in the study}

- Moyers method ${ }^{[6]}$

Probability charts at $75^{\text {th }}$ percentile levels were used to estimate the widths of permanent canines and premolars using the sum of mandibular permanent incisors.

- Tanaka and Johnston method ${ }^{[7]}$

The mesiodistal widths of permanent canine and premolars were estimated by summing 10.5 for mandibular arch and 11 for maxillary arch to half the sum of lower permanent incisors.

- Bernabé and Flores-Mir method ${ }^{[14]}$

The mesiodistal widths of permanent canine and premolars were predicted by using the following equation: $\mathrm{Y}=3.763+\left(\begin{array}{lll}0.37 & \mathrm{X} 0\end{array}\right)+\left(\begin{array}{ll}1.057 & \mathrm{X} 1\end{array}\right)+\left(\begin{array}{ll}0.366 & \mathrm{X} 2\end{array}\right)$, Where $\mathrm{Y}$ is the mesiodistal widths of the unerupted permanent canine and premolars to be predicted, $\mathrm{X} 0$ is the sum of the upper and lower permanent central incisors plus the widths of the upper permanent first molars, $\mathrm{X} 1$ is 0 for mandible and 1 for maxilla, and X2 is 0 for female and 1 for male.

The measured dimensions from the casts and the predicted values of canine and premolars were subjected to Pearson product-moment coefficients, independent $t$-test, and paired $t$-test.

\section{RESULTS}

\section{Descriptive statistical analyses of the measured tooth dimensions and sex comparisons of mesiodistal tooth widths}

The sum of mesiodistal dimensions of mandibular incisors and widths of maxillary and mandibular canine-premolar segment were subjected to statistical analysis, and the mean values and standard deviation were derived for males and females separately.
The dimensions of both maxillary and mandibular canine and premolars were greater in males than in females and the difference was highly significant statistically $(p<0.001)$. The degree of sexual dimorphism was observed to be highest in maxillary canine followed by mandibular canine [Table 2].

\section{Statistical analysis of the combined width of teeth}

The determination of sex differences between groups of teeth was performed only for groups that were to be used as summary measures in the statistical evaluation of the prediction methods [Table 3].

\section{Correlation coefficients}

In males, the correlation coefficient between the sum of mandibular incisors and the sum of canine and premolars was 0.637 and 0.685 for maxilla and mandible, respectively. This value in females was 0.55 for maxilla and 0.64 for mandible. The correlation coefficient between the sum of maxillary and mandibular central incisors and maxillary first molars, and the width of canine-premolar segment in male subjects was 0.262 and 0.268 for maxilla and mandible, respectively.

In the female subjects, this correlation was derived to be 0.693 and 0.692 for maxillary and mandibular arch, respectively.

\section{Comparisons of predicted and actual tooth size}

The two-tailed $t$ test was employed to compare the differences between the actual and predicted mesiodistal values of the sum of unerupted permanent canines, first and second premolars. All the three methods, Tanaka and Johnston, Moyers, and Bernabé and Flores-Mir exhibited overestimation when the predicted values were compared 
Table 2: Mesiodistal dimensions of canine, first premolar, and second premolar in males and females

\begin{tabular}{|c|c|c|c|c|c|c|}
\hline & \multicolumn{2}{|c|}{ Males } & \multicolumn{2}{|c|}{ Females } & \multicolumn{2}{|c|}{ Male vs female } \\
\hline & Mean (in mm) & SD & Mean (in mm) & $\mathrm{SD}^{\dagger}$ & $t$ value & Significance \\
\hline Maxillary canine & 7.89 & 0.38 & 7.32 & 0.41 & 8.41 & $<0.001^{*}$ \\
\hline Maxillary first premolar & 7.00 & 0.36 & 6.60 & 0.43 & 5.88 & $<0.001^{*}$ \\
\hline Maxillary second premolar & 6.44 & 0.42 & 6.06 & 0.41 & 5.34 & $<0.001^{*}$ \\
\hline Mandibular canine & 6.92 & 0.44 & 6.38 & 0.32 & 8.19 & $<0.001^{*}$ \\
\hline Mandibular first premolar & 7.06 & 0.34 & 6.65 & 0.42 & 6.26 & $<0.001^{*}$ \\
\hline Mandibular second premolar & 6.92 & 0.38 & 6.50 & 0.35 & 6.70 & $<0.001^{*}$ \\
\hline
\end{tabular}

Abbreviations: SD: Standard deviation; ${ }^{*}$ : Highly significant

Table 3: Mean combined mesiodistal widths of the sum of mandibular incisors and the sum of mandibular and maxillary central incisors and maxillary first molars in males and females

\begin{tabular}{|c|c|c|c|c|c|}
\hline Measurement & Male (in mm) & Female (in mm) & Mean difference (in mm) & $t$ value & Significance \\
\hline Sum of mandibular incisors & $22.63 \pm 1.22$ & $21.47 \pm 1.21$ & 1.15 & 5.54 & $<0.001^{*}$ \\
\hline Sum of mandibular and maxillary central & $47.56 \pm 5.52$ & $46.37 \pm 2.42$ & 1.19 & 1.19 & $0.105^{\dagger}$ \\
\hline
\end{tabular}

incisors and maxillary first molars

": Highly significant; ${ }^{\dagger}$ : Insignificant

with actual sum of permanent canine and premolars in males as well as females. The difference was highly significant $(p<0.001)$ [Table 4].

The simple linear regression employed by Tanaka and Johnston $^{[7]}$ is defined by the formula $Y=a+b(X)$, where $\mathrm{Y}$ is the sum of mesiodistal widths of canine and premolars of a single quadrant, $\mathrm{a}$ and $\mathrm{b}$ are constants, and $\mathrm{X}$ is the sum of mandibular incisors. The parameter of interest is the slope of linear regression (b constant). This study found $b$ coefficients of 0.511 and 0.546 for maxilla and mandible, respectively, in males, and 0.467 and 0.496 for maxilla and mandible, respectively, in females. The regression equations proposed for North Indian population are:

$$
\begin{aligned}
& \text { Males } \\
& \text { Maxilla: } \mathrm{Y}=9.783+0.511(\mathrm{X}) \\
& \text { Mandible: } \mathrm{Y}=8.415+0.546(\mathrm{X}) \\
& \text { Females } \\
& \text { Maxilla: } \mathrm{Y}=10.029+0.467(\mathrm{X}) \\
& \text { Mandible: } \mathrm{Y}=8.796+0.496(\mathrm{X})
\end{aligned}
$$

\section{DISCUSSION}

The accuracy of Tanaka and Johnston equations and Moyers probability tables is fairly good for northern European white children from whom data were originally obtained, despite a tendency to overestimate the size of unerupted teeth. ${ }^{[15]} \mathrm{A}$ further advantage is that no radiographs are required and the tables can be used for both upper and lower arch estimations. The accuracy of this prediction method when applied to population groups other than white subjects is, however, questionable because it has been well established in the literature that mesiodistal tooth sizes vary considerably between different racial groups. ${ }^{[16,17]}$ Bernabé and Flores-Mir developed multiple regression equations for Peruvian adolescents to forecast the size of unerupted teeth. ${ }^{[14]}$

Several studies have been conducted to evaluate the applicability of mixed dentition space analysis in other population groups, ${ }^{[18-23]}$ all of which disagreed with the use of Moyers and Tanaka and Johnston methods. In addition, there is some evidence of secular trends of changing dimensions of the teeth, which may require progressive modifications of mixed dentition space analysis for different populations. ${ }^{[13]}$

Since Indian literature is lacking in such data for North Indian population, keeping in view the racial, geographic, and other differences from those of the Americans, the present study attempted to establish the validity of Tanaka and Johnston equations, Moyers prediction tables, and Bernabé and Flores-Mir equations for mixed dentition analysis in a sample of North Indian population.

Plentiful studies have confirmed this existence of sexual dimorphism in tooth size with the dimensions being larger in males. ${ }^{[7,23,24-33]}$ In the current study, the magnitude of sexual dimorphism was greatest in canine, especially in maxillary arch. This degree of sexual dimorphism in tooth size is believed to have a genetic basis. ${ }^{[34]}$

In the present study, the mean value for the sum of widths of mandibular central incisors, maxillary central incisors, and first molars was $47.5571 \pm 5.5176 \mathrm{~mm}$ for males, whereas the value was $46.3665 \pm 2.4174 \mathrm{~mm}$ in female subjects. The mean difference in this value between males and females was $1.906 \mathrm{~mm}$, which was not statistically significant $(p>0.05)$. The correlation coefficients between the mesiodistal widths of canine and premolars and the combination of maxillary and mandibular central incisors and maxillary first molars in male subjects were 0.262 and 0.268 for maxilla and mandible, respectively. In the female subjects, this correlation was derived to be 0.693 and 0.692 
Table 4: Comparison of predicted values based on the methods of Moyers, Tanaka and Johnston, and Bernabé and Flores-Mir

\begin{tabular}{|c|c|c|c|c|c|c|c|c|}
\hline \multicolumn{9}{|c|}{ Males } \\
\hline \multirow[t]{2}{*}{ Prediction methods } & \multicolumn{4}{|c|}{ Maxilla } & \multicolumn{4}{|c|}{ Mandible } \\
\hline & $\begin{array}{c}\text { Predicted } \\
\text { values of } \\
\left.345^{*} \text { (in } \mathrm{mm}\right)\end{array}$ & $\begin{array}{c}\text { Actual values } \\
\text { of } 345^{*} \\
\text { (in mm) }\end{array}$ & $\begin{array}{l}\text { Difference } \\
\text { (predicted } \\
\text { actual values) } \\
\quad \text { (in mm) }\end{array}$ & $\begin{array}{l}\text { Significance } \\
\quad(p \text { value })\end{array}$ & $\begin{array}{c}\text { Predicted } \\
\text { values of } \\
345^{*}(\text { in } \mathrm{mm})\end{array}$ & $\begin{array}{l}\text { Actual values of } \\
345^{*} \text { (in mm) }\end{array}$ & $\begin{array}{c}\text { Difference } \\
\text { (predicted } \\
\text { actual values) } \\
\text { (in mm) }\end{array}$ & $\begin{array}{l}\text { Significance } \\
\quad(p \text { value })\end{array}$ \\
\hline Tanaka and Johnston & $22.31 \pm 0.61$ & $21.35 \pm 0.98$ & $0.96 \pm 0.76$ & $<0.001^{\dagger}$ & $21.80 \pm 0.60$ & $20.76 \pm 0.97$ & $1.034 \pm 0.72$ & $<0.001^{\dagger}$ \\
\hline Moyers $\left(75^{\text {th }}\right.$ percentile $)$ & $21.84 \pm 0.63$ & $21.35 \pm 0.98$ & $0.48 \pm 0.73$ & $<0.001^{\dagger}$ & $21.69 \pm 0.56$ & $20.76 \pm 0.97$ & $0.93 \pm 0.74$ & $<0.001^{\dagger}$ \\
\hline Bernabé and Flores-Mir & $22.68 \pm 2.67$ & $21.35 \pm 0.98$ & $1.93 \pm 0.77$ & $<0.001^{\dagger}$ & $21.94 \pm 0.96$ & $20.76 \pm 0.97$ & $1.18 \pm 0.97$ & $<0.001^{\dagger}$ \\
\hline \multicolumn{9}{|c|}{ Females } \\
\hline \multirow[t]{2}{*}{ Prediction methods } & \multicolumn{4}{|c|}{ Maxilla } & \multicolumn{4}{|c|}{ Mandible } \\
\hline & $\begin{array}{c}\text { Predicted } \\
\text { values of } \\
\left.345^{*} \text { (in } \mathrm{mm}\right)\end{array}$ & $\begin{array}{c}\text { Actual values } \\
\text { of } 345^{*} \\
\text { (in mm) }\end{array}$ & $\begin{array}{c}\text { Difference } \\
\text { (predicted } \\
\text { actual values) } \\
\text { (in } \mathrm{mm} \text { ) }\end{array}$ & $\begin{array}{l}\text { Significance } \\
\quad(p \text { value })\end{array}$ & $\begin{array}{c}\text { Predicted } \\
\text { values of } \\
345^{*}(\text { in } \mathrm{mm})\end{array}$ & $\begin{array}{l}\text { Actual values of } \\
345^{*} \text { (in mm) }\end{array}$ & $\begin{array}{c}\text { Difference } \\
\text { (predicted } \\
\text { actual values) } \\
\quad \text { (in } \mathrm{mm} \text { ) }\end{array}$ & $\begin{array}{c}\text { Significance } \\
(p \text { value })\end{array}$ \\
\hline Tanaka and Johnston & $21.74 \pm 0.67$ & $20.05 \pm 1.03$ & $1.67 \pm 0.90$ & $<0.001^{\dagger}$ & $21.25 \pm 0.66$ & $19.45 \pm 0.94$ & $1.79 \pm 0.80$ & $<0.001^{\dagger}$ \\
\hline Moyers $\left(75^{\text {th }}\right.$ percentile $)$ & $20.91 \pm 0.36$ & $20.05 \pm 1.03$ & $0.86 \pm 0.92$ & $<0.001^{\dagger}$ & $20.57 \pm 0.58$ & $19.45 \pm 0.94$ & $1.12 \pm 0.77$ & $<0.001^{\dagger}$ \\
\hline Bernabé and Flores-Mir & $21.98 \pm 0.90$ & $20.05 \pm 1.03$ & $1.93 \pm 0.77$ & $<0.001^{\dagger}$ & $20.92 \pm 0.90$ & $19.45 \pm 0.94$ & $1.47 \pm 0.72$ & $<0.001^{\dagger}$ \\
\hline
\end{tabular}

*: Canine premolar segment; ‘: Highly significant

for maxillary and mandibular arch, respectively. The correlation was lower than that was originally described by Bernabé and Flores-Mir. ${ }^{[14]}$ The difference can be attributed to racial and ethnic variations.

The observed correlation coefficients between the mesiodistal widths of canine and premolars and the combination of maxillary and mandibular central incisors and maxillary first molars were much lower than those derived between the sum of lower incisors and canine-premolar segments, except for maxillary arch in females. This indicates that overall, the sum of lower incisors is a better predictor of the size of permanent canine and premolars in North Indian population.

The study by Melgaco et al..$^{[35]}$ was the only study to evaluate the applicability of multiple regression linear equations proposed by Bernabé and Flores-Mir ${ }^{[14]}$ and was conducted in a population of White Brazilians whose ethnic background is similar to that of Peruvians for whom the regression equations were developed. No clinically relevant differences were found between the actual and predicted values of the size of permanent canine and premolars in males and females. The accuracy was due to similar population origins and colonization observed in this study and in the studies of Bernabé and Flores-Mir.

The correlation coefficients calculated in the present study (for maxilla in males, $r$ is 0.64 ; for mandible in males, $r$ is 0.55 ; for maxilla in females, $r$ is 0.68 and for mandible in females, $r$ is 0.64 ) showed a strong correlation for the mandibular buccal segments and also strong correlation for the maxillary buccal segments. Similar conclusions were obtained in the studies of Jaroontham and Godfrey ${ }^{[13]}$ and Tahere et al ${ }^{[36]}$

The correlation coefficients obtained were used to derive regression constants and equations. The regression equation was expressed as $Y=A+B X$, where $Y$ represented the predicted combined mesiodistal widths of canines, and first and second premolars in one quadrant (dependent variable), $X$ represented the measured mesiodistal widths of the mandibular incisors (independent variable), while A and B were the regression constants statistically derived (A was the Y-intercept and B was the slope of the regression line). In the present study, the regression constants were derived separately for males and females, as sexual dimorphism was observed in the mesiodistal dimensions of canine and premolars.

The regression parameters derived from the present study were used to formulate prediction equations that can be used clinically in tooth size predictions in a similar way to Tanaka Johnston equations. Specifically, this study derived significantly different prediction equations for prediction of mesiodistal widths of the canine premolar segments in the sample population of North Indian descent.

The regression constants and, subsequently, the prediction equations deviate in different populations from the original equations proposed by Tanaka and Johnston which was based on North European population.

\section{Conclusion}

The mixed dentition space analyses proposed by Tanaka and Johnston, Moyers, and Bernabé and Flores-Mir show overestimation of the mesiodistal widths of maxillary and mandibular canine premolar segment in both males and females. The linear regression equations derived are specific for North Indian population, hence are clinically more appropriate and reliable for this population. 


\section{Financial support and sponsorship}

Nil.

\section{Conflicts of interest}

\author{
There are no conflicts of interest.
}

\section{REFERENCES}

1. Bishara SE, Staley RN. Mixed dentition mandibular arch analysis: A step-by-step approach using the revised Hixon-Oldfather prediction method. Am J Orthod 1984;86:130-5.

2. Nance HN. Limitations of orthodontic treatment - I. Mixed dentition diagnosis and treatment. Am J Orthod 1947;33:177-223.

3. Moorrees CF, Thomsen TO, Jensen E, Yen PK. Mesio-distal crown diameters of the deciduous and permanent teeth in individuals. J Dent Res 1957;36:39-47.

4. Staley RN, Kerber RE. A revision of the Hixon and Oldfather mixed dentition prediction method. Am J Orthod 1980;78:296-302.

5. Ballard ML, Wylie WL. Mixed dentition case analysis — estimating size of unerupted permanent teeth. Am J Orthod 1947;33:754-9.

6. Moyers. Handbook of orthodontics for student and general practitioner. Chicago: Yearbook Medical publishers; 1973.

7. Tanaka MM, Johnston LE. The prediction of the size of unerupted canine and premolars in a contemporary orthodontic population. J Am Dent Assoc 1974;88:798-801.

8. Ferguson FS, Macko DJ, Sonnenberg EM, Shakun ML. The use of regression of constants in estimating tooth size in a Negro population. Am J Orthod 1978;73:68-72.

9. Hixon EH, Oldfather RE. Estimation of the sizes of unerupted canines and premolar teeth. Angle Orthod 1958;28:236-40.

10. Ingervall B, Lennartsson B. Prediction of breadths of permanent canines and premolars in mixed dentition. Angle Orthod 1978;48:62-9.

11. de Paula S, Almeida MA, Lee PC. Prediction of mesiodistal diameter of unerupted lower canines and premolars using 45 degrees cephalometric radiography. Am J Orthod Dentofacial Orthop 1995; 107:309-14.

12. Parades V, Gandia JL, Cibrian R. A new, accurate and fast digital method to predict unerupted tooth size. Angle Orthod 2006;76:14-9.

13. Jaroontham J, Godfrey K. Mixed dentition space analysis in a Thai population. Eur J Orthod 2000;22:127-34

14. Bernabé E, Flores-Mir C. Are the lower incisors the best predictors for the unerupted canine and premolars sums? An analysis of a Peruvian sample. Angle Orthod 2005;75:198-203.

15. Proffit WR, Fields HW. Contemporary Orthodontics. $3^{\text {rd }}$ Ed. St. Louis: Mosby Inc.; 2000.

16. Abu Alhaija ES, Qudeimat MA. Mixed dentition space analysis in a Jordanian population: Comparison of two methods. Int J Paediatr Dent 2006;16:104-10.

17. Schirmer UR, Wiltshire WA. Orthodontic probability tables for black patients of African descent: Mixed dentition analysis. Am J Orthod Dentofacial Orthop 1997;112:545-51.
18. al-Khadra BH. Prediction of the size of unerupted canines and premolars in a Saudi Arab population. Am J Orthod Dentofacial Orthop 1993;104:369-72.

19. Bishara SE, Jakobsen JR, Abdallah EM, Garcia AF. Comparisons of mesiodistal and buccolingual crown dimensions of the permanent teeth in the three populations from Egypt, Mexico, and the United States. Am J Orthod Dentofacial Orthop 1989;96:416-22.

20. Otuyemi OD, Noar JH. A comparison of crown size dimensions in a Nigerian and a British population. Eur J Orthod 1996;18:623-8.

21. Lee-Chan S, Jacobson BN, Chwa KH, Jacobson JS. Mixed dentition analysis for Asian-Americans. Am J Orthod Dentofacial Orthop 1998;113:293-9.

22. Nourallah AW, Gesch D, Mohammad NK, Splieth C. New regression equations for predicting the size of unerupted canines and premolars in a contemporary population. Angle Orthod 2002;72:216-21.

23. Yuen KK, Tang EL, So LL. Mixed dentition analysis for Hong Kong Chinese. Angle Orthod 1998;68:21-8.

24. Arya BS, Savara BS, Thomas D, Clarkson Q. Relation of sex and occlusion to mesiodistal tooth size. Am J Orthod 1974;66:479-86.

25. Singh SP, Goyal A. Mesiodistal crown dimensions of the permanent dentition in North Indian children. J Ind Soc Pedod Prev Dent 2006;24:192-6.

26. Richardson ER, Malhotra SK. Mesiodistal crown dimension of the permanent dentition of American Negroes. Am J Orthod $1975 ; 68: 157-64$

27. Bailit HL. Dental variation among populations. An anthropologic view. Dent Clin North Am 1975;19:125-39.

28. Altherr ER, Koroluk LD, Philips C. Influence of sex and ethnic tooth-size differences on mixed - dentition space analysis. Am J Orthod Dentofacial Orthop 2007;132:332-9.

29. Garn SM, Lewis AB, Walenga A. Evidence for a secular trend in tooth size over two generations. J Dent Res 1968;47:503.

30. Doris JM, Bernard BW, Kuftinec MM, Stom D. Biometric study of tooth size and dental crowding. Am J Orthod 1981;79:326-36.

31. Durgekar SG, Naik V. Evaluation of Moyers mixed dentition analysis in school children. Indian J Dent Res 2009;20:26-30.

32. Arslan SG, Dildes N, Kama JD, Genc C. Mixed dentition analysis in a Turkish population. World J Orthod 2009;10:135-40.

33. Lavelle CL. Secular trends in different racial groups. Angle Orthod $1972 ; 42: 19-25$

34. Garn SM, Lewis AB, Swindler DR, Kerewsky RS. Genetic control of sex dimorphism in tooth size. J Dent Res 1967;46:963-72.

35. Melgaço CA, Araujo MT, Ruellas AC. Applicability of three tooth size prediction methods for white Brazilians. Angle Orthod 2006;76:644-9.

36. nik Tahere H, Majid S, Fateme M, Kharazi fard, Javad M. Predicting the size of unerupted canines and premolars of the maxillary and mandibular quadrants in an Iranian population. J Clin Pediatr Dent 2007;32:43-8.

This is an open access article distributed under the terms of the Creative Commons Attribution-NonCommercial-ShareAlike 3.0 License, which allows others to remix, tweak, and build upon the work non-commercially, as long as the author is credited and the new creations are licensed under the identical terms.

For reprints contact: reprints@medknow.com 